\title{
Nocturnal man biting habits of mosquito species in Serian, Sarawak, Malaysia
}

\author{
Ahmad Rohani ${ }^{1}$, Ismail Zamree ${ }^{1}$, Wan Najdah Wan Mohamad Ali ${ }^{1}$, Azahari Abdul Hadi ${ }^{1}$, \\ Matusop Asmad ${ }^{2}$, David Lubim ${ }^{2}$, Zurainee Mohamed Nor ${ }^{3}$, Lee Han Lim ${ }^{1}$ \\ ${ }^{1}$ Medical Entomology Unit, Infectious Disease Research Center, Institute for Medical Research, Kuala Lumpur, Malaysia; \\ rohania@imr.gov.my, kumbanglaut@yahoo.com,wnajdah@yahoo.com, azahari@imr.gov.my, leehl@imr.gov.my \\ ${ }^{2}$ Vector Borne Disease Control Programme, Sarawak State Health Department, Kuching, Malaysia; asmadmatusop@yahoo.com, \\ davidluim@yahoo.com \\ ${ }^{3}$ Department of Parasitology, Faculty of Medicine, University of Malaya, Kuala Lumpur, Malaysia; zuraineemn@um.edu.my
}

Received 24 July 2013; revised 27 August 2013; accepted 5 September 2013

Copyright (C) 2013 Ahmad Rohani et al. This is an open access article distributed under the Creative Commons Attribution License, which permits unrestricted use, distribution, and reproduction in any medium, provided the original work is properly cited.

\begin{abstract}
Knowledge of the composition and biting habits of mosquito associated with endemic areas is important in establishing sound vector control programmes and understanding the epidemiology of vector borne diseases. The biting activity cycle of several mosquito species in Serian, Sarawak was observed and described. Collections were carried out indoors and outdoors for 12 hours from $6.00 \mathrm{pm}$ to $6.00 \mathrm{am}$ using human landing catch techniques. A total of 7271 mosquitoes comprising 27 species belonging to six genera were collected. Mansonia bonneae (23.6\%) was the predominant species caught in the study areas followed by Culex vishnui (22.3\%), Culex pseudovishnui (19.6\%) and Culex tritaenorhynchus (13.7\%). A high rate of human biting activity by Ma. bonneae was detected during November but the activity was low during January. The biting activity of Ma. bonneae was found higher outdoor compared to indoor and peaked at $\mathbf{7 . 0 0}$ pm-8.00 pm. Cx. vishnui also exhibited similar biting activity peak while Anopheles letifer exhibited biting activity peaked at 12.00 am-1.00 am. Cx. pseudovishnui showed biting patterns which were almost similar between indoor and outdoor activity and could be considered active throughout the 12 hour period.
\end{abstract}

Keywords: Mosquitoes; Biting; Nocturnal; Outdoor; Indoor

\section{INTRODUCTION}

Host feedings of mosquitoes are important implications for humans since it is by this activity that the biting rhythms of mosquitoes make an important contribution to determine periods of transmission risk and are also basic information for developing methods of personal protection against vector or nuisance mosquitoes.

A biomedical field study of the collaborative programme of the Institute Medical Research and Sabah State Health Department on research in tropical diseases was initiated in the Serian District, Sarawak. Serian, which is the main town in the district, is situated some 64 $\mathrm{km}$ from the state capital city of Kuching and is accessible by road transport. It is the focal point for villages situated in this area. Geographically, Serian District is a mountainous area with an equatorial climate which has conventional rain throughout the year. The wettest period is from November to February. The District is inhabited by a mixed number of ethnic groups of Land Dayak, Iban, Malays and Chinese. Their occupations varied with the majority of them being farmers living in villages in the interior of the District. The primary objective of the study was to determine the major mosquito fauna, in particular the vectors of malaria and filariasis. In the course of these studies, other mosquito species collected from Serian were also recorded. The species composition, biting activities and seasonal population dynamics of mosquitoes collected in the study sites were described. The study reported here was undertaken to consolidate and amplify information on distribution and abundance of mosquitoes in Serian district. These data are essential for planning programmes to alleviate health and nuisance problems caused by mosquitoes.

\section{MATERIALS AND METHODS}

The study was carried out in Balai Ringin, Serian District, 
Sarawak and was chosen based on 5 consecutive years of high malaria and filarial cases. The villages selected for the study have generally a low lying terrain with few hills and small swamps in between where dry padi and vegetables cultivations are also being practised. Field evaluations were conducted in six villages: Melikin Lama (N00 58.833' E1 1047.525'), Simpang Melikin (N00 $59.834^{\prime}$ E110 48.007'), Danau Karangas Baru (N01 $\left.{ }^{\circ} 00.161^{\prime} \mathrm{E} 110^{\circ} 47.803^{\prime}\right)$, Danau Karangas Lama (N01 $00.313^{\prime}$ E1 10 ${ }^{\circ} 47.878^{\prime}$ ), Danau Melikin (N00 $59.270^{\prime}$ $\left.\mathrm{E} 110^{\circ} 48.390^{\prime}\right)$ and Sungai Gudum (N00 58.100'

E110 $\left.47.647^{\prime}\right)$. The villages were chosen based on: high malaria and filaria incidence rate; high vector populations and village accessibility at all times of the year. However, most of these villages are in remote areas and accessible only by four-wheel drive vehicle.

Mosquitoes were caught indoors and outdoors using Human Landing Catching (HLC) technique. Twelve-hour mosquito collections were carried out bi-monthly, overnight from 7:00 pm to 7:00 am with two collectors each simultaneously stationed indoors and outdoors. All mosquitoes landing on human baits were caught using glass vials $(50 \times 19 \mathrm{~mm})$, which were subsequently plugged with cotton. Two houses were selected for each village during two collection nights for each survey. All mosquitoes were identified using standard taxonomic keys $[1,2]$ the following morning and segregated according to species, village and date. Identified female Anopheles mosquitoes were dissected to determine parity status of the ovaries. The midguts and salivary glands of parous mosquitoes were examined for malaria parasites using standard dissection techniques [3].

\section{Data Analysis for Biological Parameters}

Variation in adult mosquito densities between villages and months was compared using Friedman test. Mosquito density was expressed as number of mosquitoes collected per area and was calculated by totaling the mosquito density for all species in each sampling site. Comparisons of indoor and outdoor biting activities were analyzed by paired t-test and all data were analyzed using statistics software (SPSS 11.5 Production Facility).

\section{RESULTS}

Biting and feeding behavior of antrophophagic mosquitoes were studied in six villages in Balai Ringin, Serian District, Sarawak. Adult mosquito collections were performed for 36 nights during nine entomological surveys. Results are based on cumulative collection from all the study areas. A total of 213 Anophelines and 7059 Culicines were caught during the survey (Table 1). In this study, we detected the presence of four major species which included Ma. bonneae being the largest found in the area (23.8\%), followed closely by two Culex species, $C x$. vishnui at $22.3 \%$ and $C x$. pseudovishnui at $19,6 \%$, and lastly at $13.7 \%$ was $C x$. tritaeniorhyncus.

We examined the species for every genus present and identified four Mansonia species with Ma. bonneae being the dominating species $(92 \%)$ compared to the other species which contributed only a very small percentage: Ma. dives at 3.7\%, followed by Ma. uniformis at 3.5\% and finally Ma. annulata at $0.4 \%$. We also captured nine species of Culex mosquitoes during the study. There were two dominating species, $C x$. vishnui (30\%) and $C x$. pseudovishnui (28\%). Other Culex species detected in the area were $C x$. tritaenorhynchus (19\%), Cx. Quinquefasciatus (13\%) plus another five species which appeared in a very small percentage (between $1.8 \%-0.02 \%$ ) as follows: Cx. whitmorei, Cx. fuscocephala, Cx. Bitaeniorhynchus, Cx. gelidus, and Cx. hutchinsori. Aedes mosquitoes were also present in Balai Ringin. The species included Ae. albopictus, Ae. ceacus, and Ae. seatoi with Ae. albopictus being the dominant species detected at $83 \%$ followed by Ae. ceacus at $11 \%$ and Ae. seatoi at $6 \%$.

As far as Anopheles mosquito is concerned, there were four Anopheles species present in the study area. The highest number of Anopheles species captured was $A n$. letifer $(90 \%)$. The other $10 \%$ were represented by three other species: An. separates (7.3\%), An. tessalatus (1.8\%), and An. argyropus (0.9\%). All Anopheles mosquitoes were dissected for malaria parasites but no malaria infection was found in any of the vectors in the six study areas. Based on these findings we therefore listed species most heavily found in the study area based on individual genus as follows: An. letifer, Cx. vishnui, Cx. Peudovishnui, Ma. bonneae, Ar. durhami and Ae. allbopictus (Table 1). Friedman test indicated that significant differences did exist in mosquito collections across the villages $\left[\chi^{2}(5, \mathrm{~N}=27)=32.109, \mathrm{p}<0.05\right]$. Danau Karangas Lama (DKL) appears to be the site where highest number mosquitoes were collected during the study period.

Figure 1 demonstrated the number of species collected during each visit made to the area. Throughout the whole study period, nine visits were made to Balai Ringin, Serian, Sarawak. The most common species (detected in every visit) were $C x$. vishnui, $C x$. pseudovishnui and $M a$. bonneae. Among these three species, Ma. bonneae presented a curve in terms of its monthly collection which was almost symmetrical with the highest peak that took place in Oct'08. As for Cx. pseudovishnui and Cx. Vishnui they too showed peaks which took place slightly earlier (Aug'08) than Ma. bonneae. Peak presented by $C x$. pseudovishnui was almost two times higher than peak of Cx. vishnui. Cx. vishnui however produced a second peak which was almost two and a half times higher than its first peak during our final visit in Aug'09. A second peak 
Table 1. Mosquito species trapped in Balai Ringin, Serian Sarawak.

\begin{tabular}{|c|c|c|c|c|c|c|c|}
\hline Mosquito species & $\mathrm{DM}$ & SM & $\mathrm{DKB}$ & DKL & ML & SG & Total \\
\hline Aedes allbopictus (Skuse) & 9 & 1 & 1 & 1 & 2 & 1 & 15 \\
\hline Aedes caecus Theobald & 2 & 0 & 0 & 0 & 0 & 0 & 2 \\
\hline Aedes seatoi Huang & 1 & 0 & 0 & 0 & 0 & 0 & 1 \\
\hline Anopheles argyropus (Swellengrebel) & 0 & 0 & 1 & 0 & 0 & 0 & 1 \\
\hline Anopheles letifer Sandosham & 12 & 8 & 34 & 58 & 32 & 58 & 202 \\
\hline Anopheles separatus Leicester & 0 & 1 & 1 & 1 & 5 & 0 & 8 \\
\hline Anopheles tessalatus Theobald & 0 & 0 & 0 & 0 & 0 & 2 & 2 \\
\hline Armigeres confuses Edwards & 0 & 0 & 0 & 2 & 0 & 0 & 2 \\
\hline Armigeres durhami (Edwards) & 0 & 1 & 1 & 1 & 2 & 0 & 5 \\
\hline Armigeres sp 1 & 4 & 0 & 0 & 0 & 0 & 0 & 4 \\
\hline Armigeres sp 2 & 1 & 0 & 0 & 0 & 0 & 0 & 1 \\
\hline Culex bitaeniorhyncus Giles & 14 & 0 & 6 & 7 & 1 & 1 & 29 \\
\hline Cx. fuscocephela Theobald & 4 & 1 & 4 & 7 & 26 & 0 & 42 \\
\hline Cx. gelidus Theobald & 6 & 0 & 1 & 4 & 2 & 0 & 13 \\
\hline Cx. hutchinsori Barraud & 0 & 1 & 0 & 0 & 0 & 0 & 1 \\
\hline Cx.pseudovishnui Colless & 247 & 32 & 402 & 585 & 119 & 41 & 1426 \\
\hline Cx. quinquefasciatus Say & 195 & 11 & 260 & 179 & 24 & 5 & 674 \\
\hline Cx. sinensis Theobald & 0 & 0 & 6 & 1 & 0 & 0 & 7 \\
\hline Cx. sitiens Wiedemann & 48 & 0 & 54 & 118 & 25 & 1 & 246 \\
\hline Cx. tritaenorhyncus Giles & 161 & 19 & 294 & 375 & 103 & 42 & 994 \\
\hline Cx. vishnui Theobald & 209 & 20 & 406 & 743 & 164 & 77 & 1619 \\
\hline Cx. whitmorei (Giles) & 20 & 3 & 29 & 25 & 10 & 5 & 92 \\
\hline Coquilettidia sp. & 0 & 0 & 0 & 1 & 0 & 0 & 1 \\
\hline Ma. annulata (Leicester) & 1 & 1 & 0 & 2 & 3 & 2 & 9 \\
\hline Ma. bonneae Edwards & 190 & 170 & 161 & 230 & 648 & 330 & 1729 \\
\hline Ma. dives (Schiner) & 11 & 5 & 7 & 18 & 14 & 14 & 69 \\
\hline Ma. uniformis (Theobald) & 4 & 3 & 14 & 31 & 9 & 6 & 67 \\
\hline TOTAL & 1139 & 277 & 1682 & 2389 & 1189 & 575 & 7271 \\
\hline
\end{tabular}

ML: Melikin Lama; SM: Simpang Melikin; DKB: Danau Karangas Baru; DKL: Danau Karangas Lama; DM: Danau Melikin; and SG: Sungai Gudum.

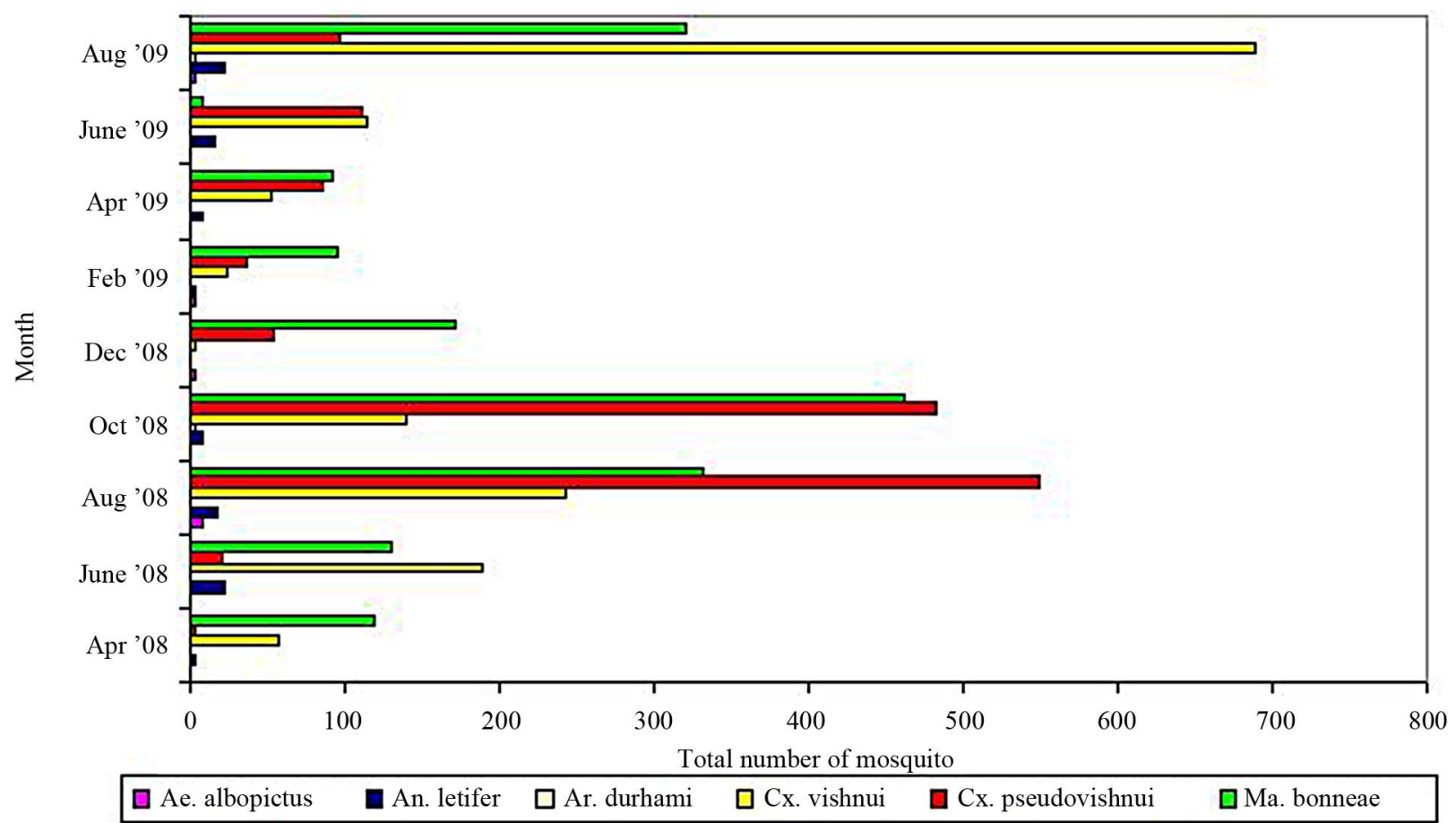

Figure 1. Total number of adult mosquitoes collected per trip. 
was also demonstrated by Ma. bonneae during that same visit but the peak was not as high as the first one and it was also lower than that of $C x$. vishnui.

An. letifer was detected in seven out of our nine visits. They were not detected during our Apr'08 and Dec'08 visits. Although it was the most dominant species among the Anopheles mosquito, compared to species from other genus, their total number in those individual seven visits were considered very low $(<50)$. As for Ae. albopictus and $A r$. durhami, they were only detected once out of the nine visits. Ae. albopictus was detected in Aug'08 while Ar. durhami in Oct'08. Similar to An. letifer, the number of adults collected for both species was obviously very low compared to other species from other genus (Figure 1).

We then examined the number of adult mosquitoes collected outdoor and indoor for every visit made. The biting habit of Ma. bonneae within 12 hour period (dawn to dust) showed that this mosquito started biting around 7:00 pm and was very active and reached its highest peak at 8:00 pm. The biting activity began to drop drastically when approaching 9:00 pm and continued to drop further around 11:00 pm and then leveled off from 11:00 pm until $6 \mathrm{am}$. The biting activity of Ma. bonneae was found higher outdoor $(110.333 \pm 91.866)$ compared to indoor $(33 \pm 28.939)$ as shown in Figure 2.

Figure 3 shows the biting activity of $C x$. vishnui indoor and outdoor. Cx. vishnui also started its biting activity after 7:00 pm for both indoor and outdoor. The outdoor activity was very active and reached its highest peak at 8:00 pm, while indoor activity took another two hours to reach its highest peak. At this point (10:00 pm), the outdoor activity dropped to its lowest level throughout the 12 hour period. From that point onwards, both

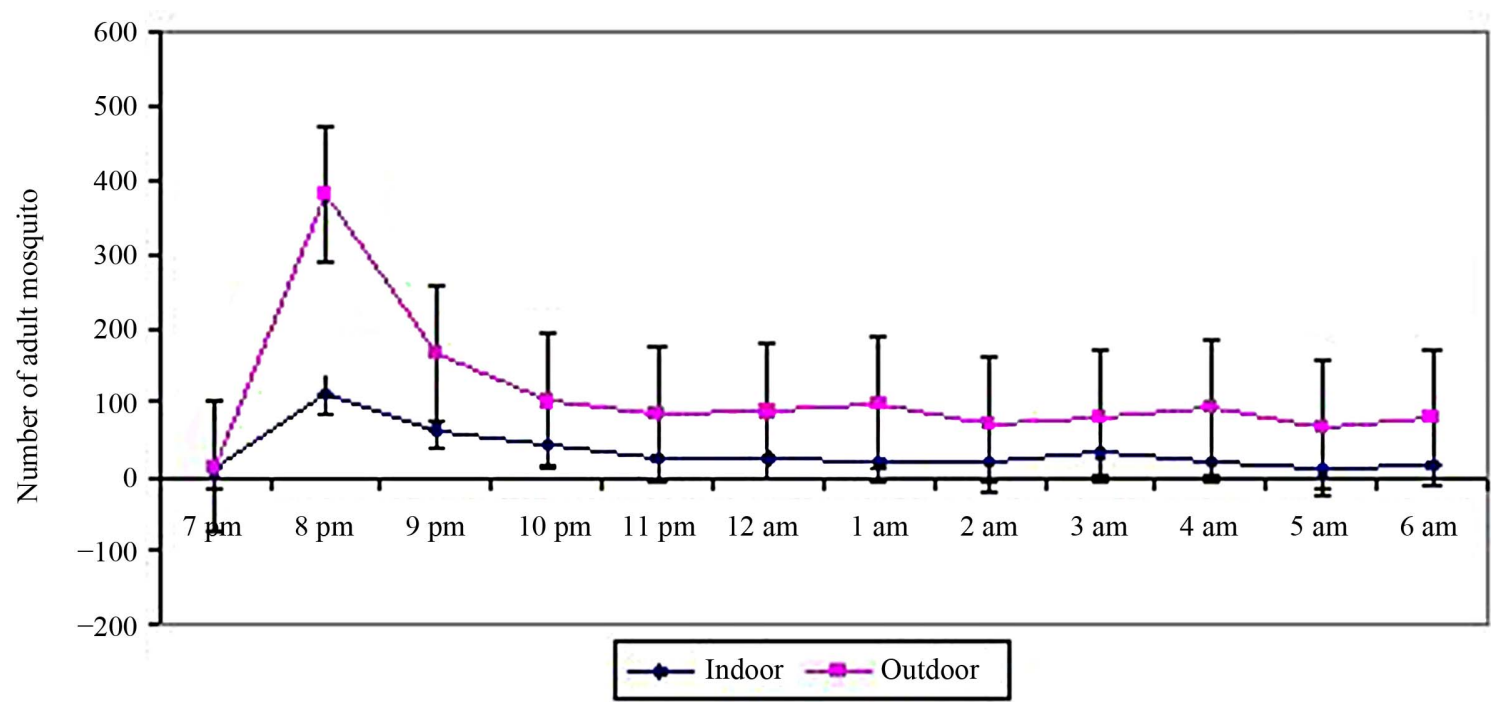

Figure 2. Outdoor and Indoor biting activities of Mansonia bonnae in the study areas.

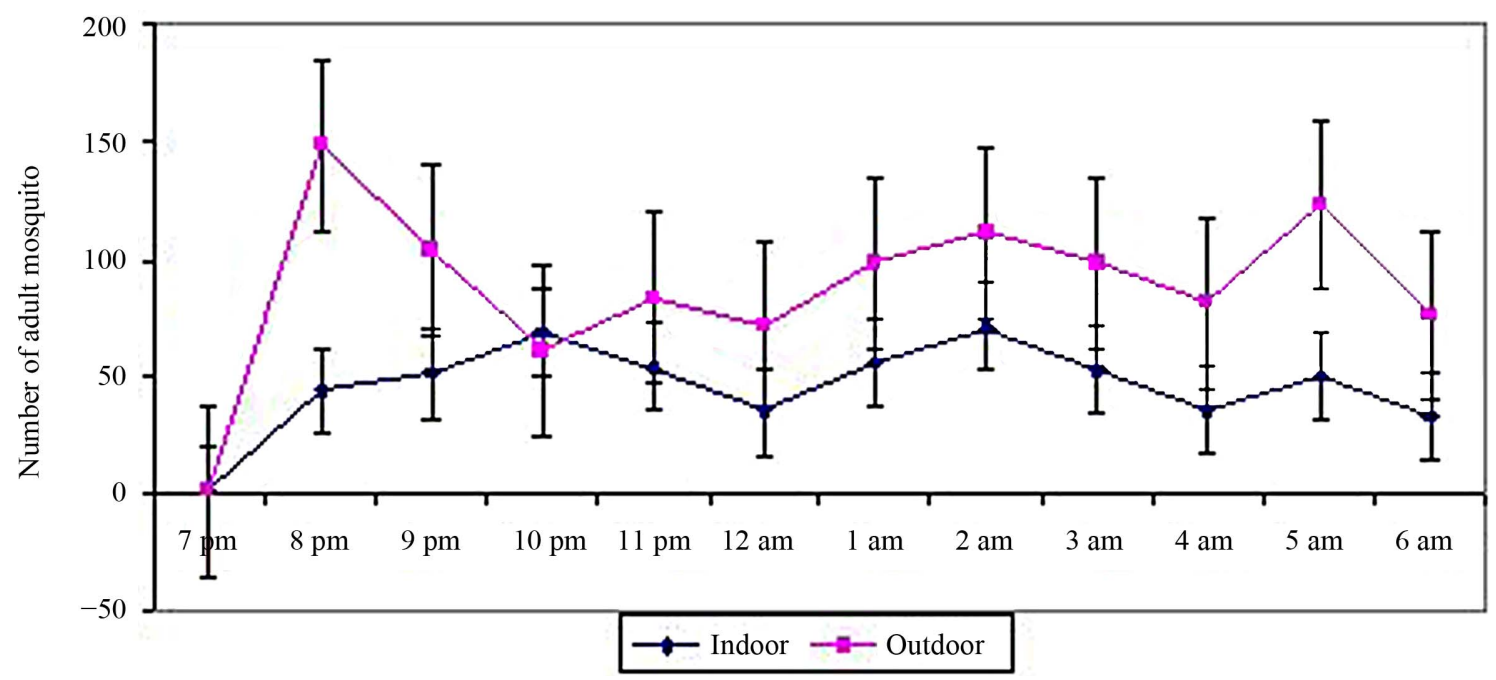

Figure 3.Outdoor and Indoor biting activities of Culex vishnui in the study areas. 
indoor and outdoor activities were seen to display almost similar biting patterns. For this species too, it was clearly demonstrated that the outdoor biting activity (88.167 \pm 36.548) was slightly higher than the indoor activity (46.083 \pm 18.652 ). This species however, presented the type of biting activity which was different from Ma. bonneae since the number of biting activity recorded were fluctuating throughout the 12-hour period, which was not shown by Ma. bonneae.

As for Cx. pseudovishnui, this species too started its biting activity after 7:00 pm outdoor and indoor and in general, it also presented higher outdoor biting activity than indoor although the biting activity curves tend to overlap few times (at 12:00 am and 3:00 am) during the 12 hour period (Figure 4). Both indoor $(44.75 \pm 22.596)$ and outdoor $(75.333 \pm 32.9)$ biting activity curves indicated active activity throughout the 12 hour period al- most similar to that of $C x$. vishnui.

Another Culex species which we were able to examine in terms of its biting activity was $C x$. tritaeniorhyncus. Figure 5 showed an interesting finding where the highest number of biting was 140 bites which were three times higher than the other Culex species. It also has biting patterns which were almost similar between indoor and outdoor activity with indoor activity $(22.667 \pm 13.262)$ being lower than the outdoor activity (59.75 \pm 32.949$)$. Outdoor biting activity presented three peaks, one peak during the early part of the night $(8 \mathrm{pm})$ and others during early morning (12 am and 2 am) while indoor activity, although three peaks were also presented, two of three peaks were presented during the early part of the activity ( $8 \mathrm{pm}$ and $10 \mathrm{pm})$ and the other was at $3 \mathrm{am}$. In general, biting activity could be considered active throughout the 12 hour period.

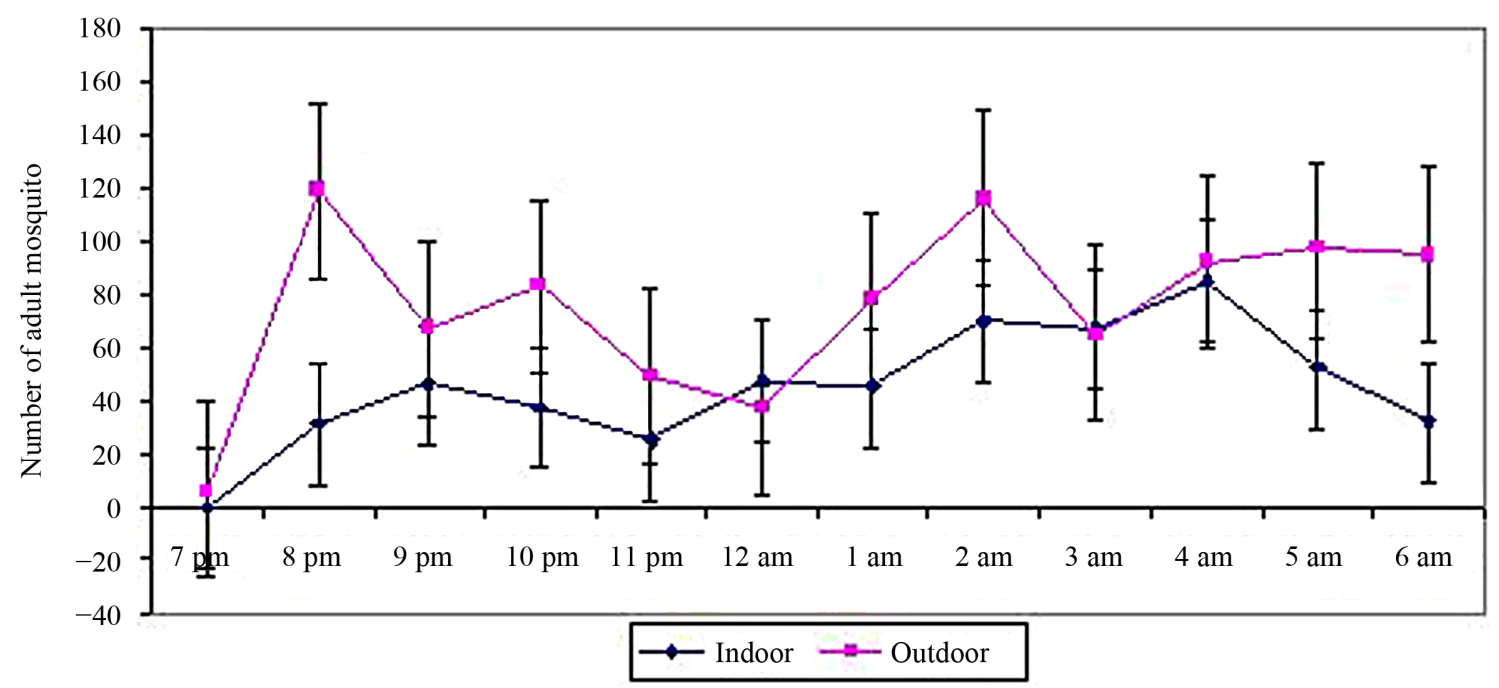

Figure 4. Outdoor and Indoor biting activities of Culex pseudovishnui in the study areas.

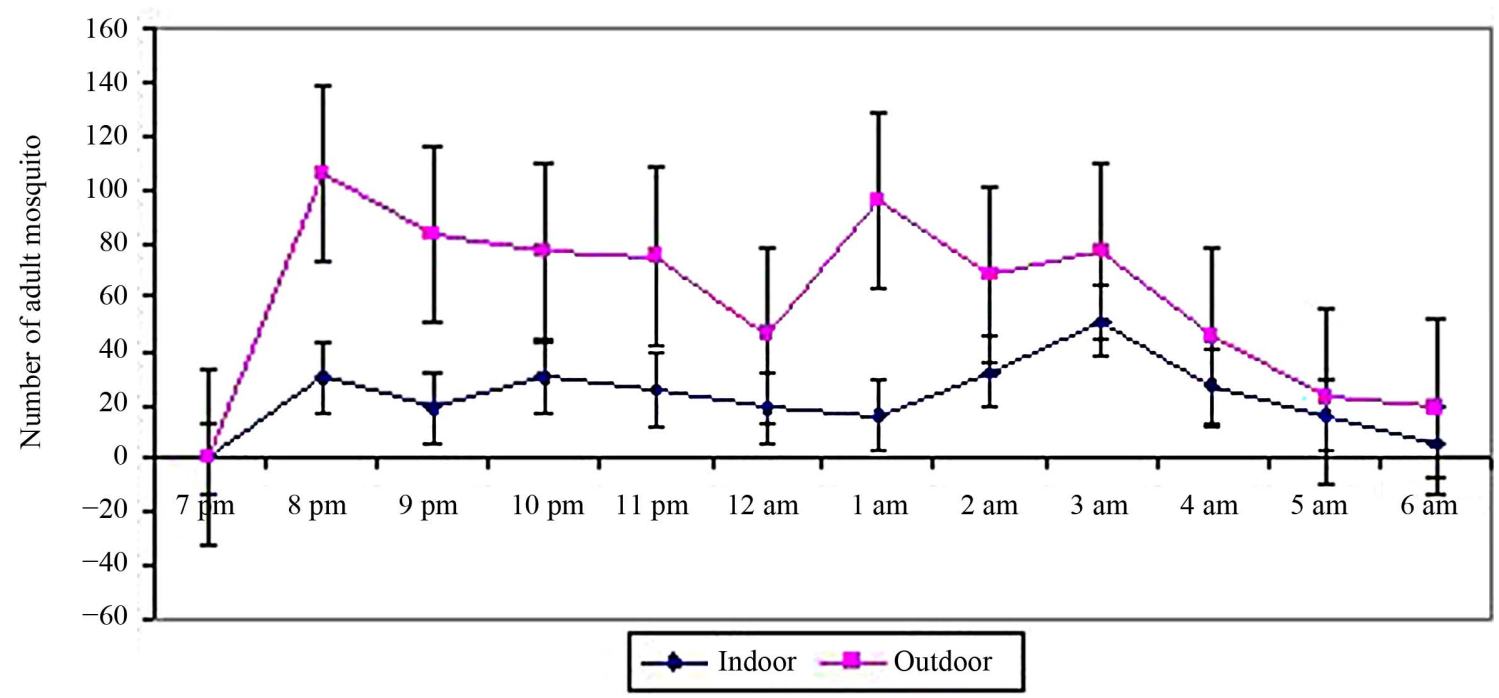

Figure 5. Outdoor and Indoor biting activities of $C x$. tritaeniorhynchus in the study areas. 
The overall indoor and outdoor biting activity of $A n$. letifer for the study areas is shown in Figure 6. An. letifer first bites were recorded as early as 7:00 - 8:00 PM. The highest peak of outdoor biting activity was observed at 1:00 am, while the indoor biting activity highest peaks were observed between 9:00 pm - 10:00 pm and 2:00 am. The overall outdoor biting activity $(6.167 \pm$ 3.486) was higher than the overall indoor biting activity $(2.083 \pm 1.505)$. There was a significant difference between outdoor and indoor biting activity for An. letifer $(\mathrm{t}$ $=-4.867, \mathrm{P}<0.05)$. Based on the number of bites made by this species, An. letifer did not seem to bite as many (the number of highest bite was around 4) as the previous species described earlier (120 bites for Ma. bonnie, 50 bites for $C x$. vishnui and around 50 bites for $C x$. Pseudovishnui either outdoor or indoor). They did however bite at every hour throughout the 12-hour period except at 5:00 AM.

\section{DISCUSSION}

Deforestation and development of large scale oil palm plantation have been taking place in many parts of Serian areas for the past 10 years and there is widespread concerns that these projects can have significant effects on human health [4]. New agroforestry, opening of new roads and population migration may increase heterogenous distribution of vectors in these areas. Changes in the environment may have direct or indirect impact on the behaviour and bionomics of mosquitoes [5]. Local climatic parameters play an important role in determining the distribution and abundance of these vectors because the distribution of vector-borne diseases is restricted by the climate tolerance limits of their vectors [6]. Many studies have shown that forest modification and clearing have a negative effect on biodiversity $[7,8]$ and the associated land use change has been linked to emerging and re-emerging diseases [9]. Land use change potentially has serious consequences for human health in association with mosquito-borne diseases [10], and must be monitored to avoid public health disasters. As such, on-going entomological surveillance, continued improvements and implementations of control programmes are important in managing the spread of the diseases transmitted by vector mosquitoes. However, the methods and locations of mosquito collection may significantly affect the catch size and species detected in the study areas [11].

Data derived from adult mosquito surveillance provides information essential in monitoring potential vector activity, setting action thresholds and evaluating control efforts. The present study used adult mosquito surveillance to monitor the presence of species and relative abundance of mosquitoes. The study conducted in Serian, Sarawak produced data that revealed the presence of 27 mosquito species. The biting activity of the mosquito was studied as it allows understanding of the biting cycles of the vector species, determination of nuisance level and detection of possible disease transmission. In this study, we detected the presence of five major species which included Ma. bonneae being the largest found in the area, followed closely by $C x$. vishnui, Cx. Pseudovishnui, Cx. tritaeniorhyncus and An. letifer. This study indicates that all the major species readily seek hosts in outdoor venues.

$A n$. letifer was identified as the vector of malaria in Sarawak [4] and largely responsible for malaria epidemics and intense focal transmission in logging camp and road construction sites in Sarawak. Cultivation and planting of oil palms favour the breeding of An. letifer due to the availability of open and block swamps [4]. There is

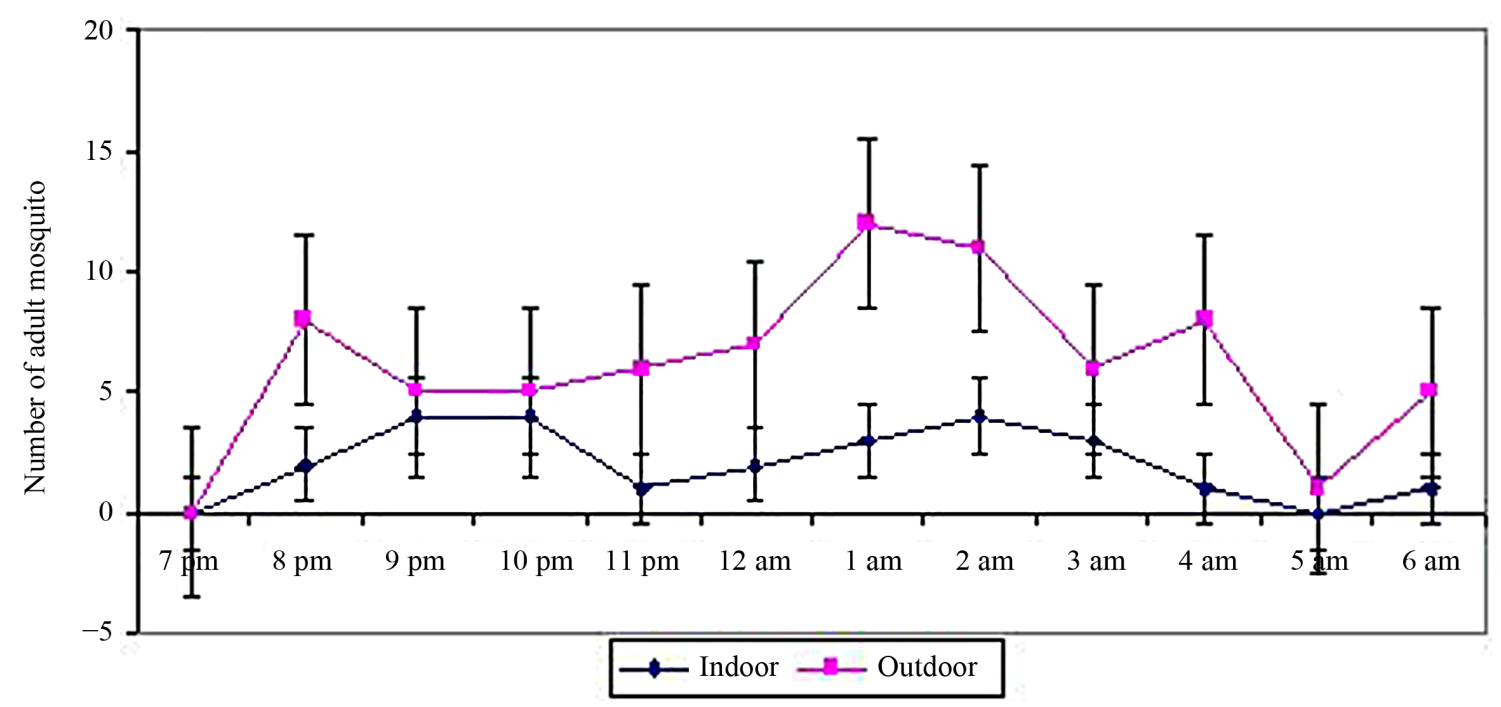

Figure 6. Out-door and In-door biting activities of An. letifer in the study areas. 
no evidence for malaria transmission by An. separates, An. tessalatus, and An. argyropus which were also collected during the study period. The study on the biting habits of An. letifer showed that this species bites both indoor and outdoor, although more were found biting outdoor than indoor. This proved that this vector is endophilic and control of this malaria vector by indoor residual spray is a good strategy since mosquitoes do enter and rest in treated houses and have sufficient contact with sprayed surface before and after biting humans. The data presented in this study, along with the recent work by Russell et al. [12] and Reddy et al. [13] suggest that the long-term indoor application of residual insecticides contributes toward an increased tendency for outdoor feeding among malaria vector populations.

Among the Mansonia species collected during the survey, Ma. bonneae was the predominant species. Ma. bonneae is an important vector of brugian filariasis in Serian [14]. Macdonald et al. [15] and Chang et al. [16] reported that Ma. bonneae have been found breeding in swampy patches near the river. There were extensive areas of swamp forest near by and scattered pools in the study areas which probably supported Ma. bonneae. The peak numbers of Ma. bonneae occurred in August and October in Serian. This was different from the single peak, in October, recorded in a peat swamp forest of Sungai Kolok District, Narathiwat Province, Thailand [17].

Aedes mosquito was also collected in Balai Ringin but in very low number. Among the Aedes, Ae. albopictus was the dominant species, followed by Ae.ceacus and Ae. seatoi. Ae. albopictus is one of the commonest Aedes species in Malaysia. It is also known to be a vector of dengue and chikungunya in Malaysia. It occurs in all ecotypes in towns, villages, forest fringe and coastal areas. However, bias may have been introduced by night-time sampling, since Ae. albopictus is prominently a day biter. The presence of Ae. abopictus in the study sites was undoubtedly related to the availability of domestic breeding habitats such as artificial water containers. Due to lack of a piped water supply in the study areas, the practice of storing rain water encouraged the proliferation and breeding of Ae. albopictus in numerous water tanks and jars. Established agricultural settlements in rural areas could also increase the Ae. albopictus population, thus spread of rural dengue fever among the rural communities in Sarawak [18].

These data provide a better understanding of the taxonomy, population density and seasonal distribution of potential mosquito vectors of disease within Balai Ringin, Serian and allow for the development of appropriate vector and disease prevention strategies that target vector population. Further studies should be carried out to supplement the observations which have been recorded.

\section{ACKNOWLEDGEMENTS}

The authors are grateful to the Director-General of Health, Malaysia for permission to publish this paper and Director, Institute for Medical Research, Kuala Lumpur for support. We especially thank the staff of Medical Entomology Unit of IMR and Vector Control Unit, Kuching, Sarawak, without whose diligence and hard work under difficult field conditions this research would not have been accomplished. This study was funded by a National Institutes of Health research grant (06CAM-04-04), Ministry of Health, Malaysia.

\section{REFERENCES}

[1] Russell, P.F., West, L.S., Manwell, R.D. and Macdonald, G. (1963) Practical malariology. 2nd Edition, Oxford University Press, London, 750p.

[2] Reid, J.A. (1968) Anopheline mosquitoes in Malayi and Borneo. Institute for Medical Research, Kuala Lumpur, $520 \mathrm{p}$.

[3] World Health Organization (WHO) (1975) Manual on practical entomology in malaria. The WHO Division of Malaria and Other Parasitic Disease, Part II, Geneva, $191 \mathrm{p}$.

[4] Chang, M.S., Hii, J., Buttner, P. and Mansoor, F. (1997) Changes in abundance and behavior of vector mosquitoes induced by land use during development of oil plantation in Sarawak. Transactions of the Royal Society of Tropical Medicine and Hygiene, 91, 382-386.

[5] De Las Llagas, L. (1985) Impact of ecological changes on Anopheles vectors of malaria in some countries in Southeast Asia. Southeast Asian Journal Tropical Medicine Public Health, 16, 46-48.

[6] Martin, V., Chevalier, V., Ceccato, P., Anyamba, A., De Simone, L., Lubroth, J., De La Rocque, R. and Domenech, J. (2008) The impact of climate change on the epidemiology and control of Rift Valley fever. Review Science Technology, 27, 413-426.

[7] Fitzherbert, E.B., Struebig, M. J., Morel, A., Danielsen, F., Bruhl, C.A., Donald, P.F. and Phalan, B. (2008) How will oil palm expansion affect biodiversity? Trends in Ecology and Evolution, 23, 538-545.

[8] Sodhi, N.S., Posa, M.R.C., Lee, T.M., Bickford, D., Koh, L.P. and Brook, B.W. (2010) The state and conservation of Southeast Asian biodiversity. Biodiversity Conservation, 19, 317-328.

[9] Patz, J.A., Graczyk, T.K., Geller, N. and Vittor, A.Y. (2000) Effects of environmental change on emerging parasitic diseases. International Journal for Parasitology, 30, 1395-1405.

[10] Vanwambeke, S.O., Lambin, E.F., Eichhorn, M.P., Flasse, S.P., Harbach, R.E., Oskam, L., Somboon, P., Vvan Beers, S., van Benthem, B.H.B., Walton, C. and Butlin, R.K. (2007) Impact of land-use change on dengue and malaria in Northern Thailand. EcoHealth, 4, 37-51.

[11] Turell, M.J., Sardelis, M.R., Jones, J.W., Watt, D.M., Fernandez, R., Carbajal, F., Pecor, J.E. and Klein, T.A. (2008) Seasonal distribution, biology, and human attraction patterns of mosquitoes (Diptera: Culicidae) in a rural 
village and adjacent forested site near Iquitos, Peru. Journal Medical Entomology, 45, 1165-1172.

[12] Russel, T.L., Govella, N. J., Azizi, S., Drakeley, C.J., Kachur, S.P. and Killeen G.F. (2011) Increased proportions of outdoor feeding among residual malaria vector populations following increased use of insecticide-treated nets in rural Tanzania. Malaria Journal, 10, 80.

[13] Reddy, M.R., Overgaard, H.J., Abaga, S., Reddy, V.P., Caccone, V., Kiszewski, A.E. and Slotman, M. (2011). Outdoor host seeking behaviour of Anopheles gambiae mosquitoes following initiation of malaria vector control on Bioko Island, Equatorial Guinea. Malaria Journal, 10, 184. http://dx.doi.org/10.1186/1475-2875-10-184

[14] Rubis, P., Chang, M.S., Nagum, A.J. and Jau, J.L. (1981) Parasitological and entomological studies on filariasis in seven villages, Serian District, Sarawak, East Malaysia. Southeast Asian Journal Tropical Medicine Public Health, 12, 30-35.
[15] Macdonald, W.W., Smith, C.E.G. and Webb, H.E. (1965) Arbovirus infections in Sarawak: Observations on the mosquitoes. Journal Medical Entomology, 1, 335-347.

[16] Chang, M.S., Chan, K.L. and Ho, B.C. (1993) Control of Mansonia mosquitos, vectors of brugian filariasis in Sarawak, Malaysia. Southeast Asian Journal of Tropical Medicine and Public Health, 24, 93-104.

[17] Apiwathnasorn, C., Samung, Y., Prummongkol, S., Asavanich, A., Komalamisra, N. and McCall, P. (2006) Bionomics studies of Mansonia mosquitoes inhibating the peat swamp forest. Southeast Asian Journal of Tropical Medicine and Public Health, 37, 272-278.

[18] Cheah, W.L., Chang, M.S. and Wang, Y.C. (2006) Spatial, environmental and entomological risk factors analysis on a rural dengue outbreak in Lundu District in Sarawak, Malaysia. Tropical Biomedicine, 23, 85-96. 